Review

\title{
A Systematic Review of the Legal Considerations Surrounding Medicines Management
}

\author{
Mojtaba Vaismoradi ${ }^{1, *(\mathbb{D}}$, Sue Jordan ${ }^{2}\left(\right.$, , Patricia A. Logan ${ }^{3}\left(\mathbb{D}\right.$, Sara Amaniyan ${ }^{4}$ and Manela Glarcher ${ }^{5}$ \\ 1 Faculty of Nursing and Health Sciences, Nord University, 8049 Bodø, Norway \\ 2 Department of Nursing, Swansea University, Swansea SA2 8PP, UK; s.e.jordan@swansea.ac.uk \\ 3 Faculty of Science, Charles Sturt University, Bathurst 2795, Australia; plogan@csu.edu.au \\ 4 Student Research Center, Semnan University of Medical Sciences, Semnan 3514799442, Iran; \\ s.amaniyan98@semums.ac.ir \\ 5 Institute of Nursing Science and Practice, Paracelsus Medical University, 5020 Salzburg, Austria; \\ manela.glarcher@pmu.ac.at \\ * Correspondence: mojtaba.vaismoradi@nord.no; Tel.: +47-75517813
}

Citation: Vaismoradi, M.; Jordan, S.; Logan, P.A.; Amaniyan, S.; Glarcher, M. A Systematic Review of the Legal Considerations Surrounding Medicines Management. Medicina 2021, 57, 65. https://doi.org/ 10.3390/medicina57010065

Received: 4 December 2020 Accepted: 10 January 2021 Published: 13 January 2021

Publisher's Note: MDPI stays neutral with regard to jurisdictional clai$\mathrm{ms}$ in published maps and institutional affiliations.

Copyright: (C) 2021 by the authors. Licensee MDPI, Basel, Switzerland. This article is an open access article distributed under the terms and conditions of the Creative Commons Attribution (CC BY) license (https:// creativecommons.org/licenses/by/ $4.0 /)$.

\begin{abstract}
Background and Objectives: There is a paucity of integrated knowledge regarding legal considerations required to ensure patient safety through safe medicines management. This study explores the legal considerations surrounding medicines management, providing a synthesis of existing knowledge. An integrative systematic review of the current international knowledge was performed. Materials and Methods: The search encompassed the online databases of PubMed (including Medline), Scopus, CINAHL, and Web of Science using MeSH terms and relevant keywords relating to the legal considerations of medicines management in healthcare settings. Results: The search process led to the identification of 6051 studies published between 2010 and 2020, of which six articles were found to be appropriate for data analysis and synthesis based on inclusion criteria. Research methods were varied and included qualitative interviews, mixed-methods designs, retrospective case reports and cross-sectional interrupted time-series analysis. Their foci were on the delegation of medicines management, pharmacovigilance and reporting of adverse drug reactions (ADRs) before and after legislation by nurses, physicians and pharmacists, medico-legal litigation, use of forced medication and the prescription monitoring program. Given the heterogenicity of the studies in terms of aims and research methods, a meta-analysis could not be performed and, therefore, our review findings are presented narratively under the categories of 'healthcare providers' education and monitoring tasks', 'individual and shared responsibility', and 'patients' rights'. Conclusion: This review identifies legal aspects surrounding medicines management, including supervision and monitoring of the effects of medicines; healthcare providers' knowledge and attitudes; support and standardised tools for monitoring and reporting medicines' adverse side effects/ADRs; electronic health record systems; individual and shared perceptions of responsibility; recognition of nurses' roles; detection of sentinel medication errors; covert or non-voluntary administration of medication, and patient participation.
\end{abstract}

Keywords: clinical practice; law; legal; adverse drug reactions; pharmacovigilance; medicines management; patient safety

\section{Introduction}

Health care is a complex system in which patients often experience harm resulting from the healthcare process itself $[1,2]$. It is too frequently accompanied by adverse events and medical errors [3], which are often preventable [4]. The World Health Organization (WHO) indicates that harm is caused in approximately one in 10 hospitalized patients, with at least $50 \%$ of these harms being preventable. Estimates show that 421 million hospitalizations take place worldwide every year and that during hospitalization about 42.7 million adverse events occur, and $18.3 \%$ of adverse events are attributed to medication errors [5]. A systematic review of 25 studies conducted in 27 countries showed that $2.9-21.9 \%$ of patients 
were affected by at least one adverse event, many of which were medication-related, and $34.3-83 \%$ could be prevented [6]. Beside deaths and serious adverse drug reactions (ADRs) in community settings, 128,000 patient deaths from prescribed medicines are reported annually in hospitals in the USA [7]. Therefore, measures for improving the quality of healthcare ensure or optimise patient safety "as the absence of preventable harm to a patient during the process of health care and reduction of risk of unnecessary harm associated with health care to an acceptable minimum" [8]. These efforts have gained critical international significance: in 2004, the founding of the World Alliance for Patient Safety by the WHO provided an initiative to focus on and improve the quality of care and patient safety. This alliance cooperates with health-related partners, e.g., with the 24 participating ministries of health or National Patient Safety Agencies, to achieve global improvement in healthcare, including the prescribing, dispensing and administering of medicines [9]. The European Commission (EC) intensified further developments to improve the safety of health care in Europe with the Luxembourg Declaration on Patient Safety in 2005. This indicates that $50 \%$ of all preventable adverse events are a consequence of 'medication errors', and has led to the development of specific recommendations to Europe-wide institutions, national authorities and healthcare providers [10,11].

\section{Medicines Management and Law}

The overall goal of healthcare interventions is to ensure safe and high-quality patient care [12] through the safe and effective use of medications for the treatment of diseases [13]. There is a growing demand for the prescription of medications to treat age-related and chronic diseases worldwide. As an example, in Organisation for Economic Co-operation and Development (OECD) countries in 2017, the retail trade in pharmaceuticals accounted for one-fifth of all healthcare expenditures, averaging $\$ 564$ per person [14]. Medicines have the ability to prevent, treat and cure diseases, but errors in the medication process that determines how medicines are used can cause damage. Therefore, the nature of pharmacotherapy demands that systems be in place to ensure the correct use of medicines, and that all transactions relating to medications be governed by appropriate laws and regulations [10].

According to the WHO Constitution (1946), "the highest attainable standard of health is a fundamental right of every human being". Therefore, legal considerations are taken up by all countries through domestic or constitutional law to ensure access to high quality and safe health care [15]. It regulates behaviours or procedures that must be followed by individuals for maintaining human health, controlling or changing personal and professional behaviours [3].

Medicines management, as the handling of medications and medicinal products by healthcare professionals, consists of prescribing, dispensing, distributing, administration, patient education, follow up and monitoring, and is regulated by law $[13,16]$. In most cases, such laws contain a legal definition of a medicine, which also influences what can be purchased over the counter and when a prescription is required to obtain a medication. This provides a framework for governments to monitor the use of medications in the workplace, and defines how and according to which guidelines medications can be administered, including provisions for emergency situations [13]. Nonetheless, there are international differences in regulations for medicines management. In the United States, the Food and Drug Administration (FDA) of the U.S. Department of Health and Human Services pursues the protection of public health, which includes monitoring the safety and efficacy of medications. In many ways, the Drug Amendments of 1962 by the FDA is a model followed by other countries [17]. Within the European Union (EU), medicines law consists of European Commission directives and regulations that member states incorporate into national law [10].

Principles of medicines management developed based on laws and regulations should be unambiguously communicated through guidelines to healthcare professionals for indispensable use in clinical practice $[18,19]$. From the prescription to the administration 
of a medicine to a patient, physicians, nurses and pharmacists collaborate as a multidisciplinary team. However, problems can arise due to the unclear legal arrangements for medicines management [18]. Costs arising from additional hospital stays, litigation costs, hospital-acquired infections, loss of income, disability, and medical expenses have been reported as $\$ 6$ to $\$ 29$ billion annually [5].

Legal considerations to ensure patient safety through safe medicines management are therefore at the top of the political agenda, but there is a paucity of integrated knowledge. Accordingly, this systematic review of the international literature aims to answer the following question: what are the legal considerations for medicines management in healthcare settings?

\section{Materials and Methods}

\subsection{Design}

A systematic review of literature was carried out as an explicit and objective research method for data collection and knowledge synthesis to reach our study aim [20]. An integrative approach to systematic reviewing was chosen, involving both qualitative and quantitative studies. It aims at summarising empirical or theoretical literature to provide a more comprehensive understanding of healthcare problems and can inform future research, clinical practice, and policy initiatives [21].

\subsection{Search Method and Inclusion Criteria}

The research protocol was developed (Appendix A) and three authors (MV, SA, MG) participated in the search process using four large online international databases that cover the majority of life sciences' citations: PubMed (including Medline), Scopus, CINAHL and Web of Science. A reference librarian was approached to check the search process. The search aimed to retrieve articles published in English in the decade from 2010 to 2020.

To maximise the number of studies retrieved, a pilot search in general and specialised databases, based on our experience of medicines management, was undertaken. This identified all $\mathrm{MeSH}$ terms and all relevant keywords relating to the 'legal considerations' for 'medicines management'. Boolean operators (AND, OR) were used to build search phrases and search titles and abstracts. Grey literature on policy documents, clinical guidelines and cross-references from bibliographies were used to improve the search coverage.

Inclusion criteria were empirical studies with a focus on legal considerations of medicines management in clinical practice, in short-term and long-term healthcare settings, and published in online peer-reviewed scientific journals. Thus, reviews, commentaries, letters, conference proceedings, and those studies with a concentration on medicines management in places other than healthcare settings were excluded. The authors independently screened the titles, abstracts, and full texts of the retrieved studies, held discussions, and reached agreement regarding the inclusion of selected studies based on the inclusion criteria.

\subsection{Quality Appraisal}

Appropriate tools to the selected studies' methods were used, including the Strengthening the Reporting of Observational Studies in Epidemiology (STROBE) (for crosssectional studies, maximum score 30) [22], the Critical Appraisal Skills Programme (CASP) for qualitative studies (maximum score 10) [23], Mixed Methods Appraisal Tool (MMAT) (maximum score 17) [24], and Joanna Briggs Institute (JBI) Critical Appraisal Checklist for Case Reports (maximum score 8) [25]. Overall, the final decision on the importance and methodological quality of each study for inclusion or exclusion was made after holding discussions between the authors and reaching agreement.

\subsection{Data Abstraction and Knowledge Synthesis}

A pre-piloted data extraction table was developed to import data from selected studies and categorise them according to: author's name, publication year, country, design, sample size and setting, and main findings concerning legal aspects of medicines management in 
healthcare settings. Before the full data extraction, the table was pilot-tested to ensure that it suited the review aim by including the required data for knowledge analysis [20].

Variations within the selected studies in terms of aims and methods precluded a meta-analysis. Therefore, the review findings are presented narratively based on the Preferred Reporting Items Systematic Reviews and Meta-Analysis (PRISMA) statement [26]. Categories were developed by the authors based on differences and similarities in the studies' findings. The authors undertook discussions to reach agreements on assigning the studies' findings into the categories.

\section{Results}

\subsection{Search Results and Study Selections}

The literature search in the databases led to the retrieval of 6051 articles in total from four databases (Figure 1). Deletion of duplicate titles and irrelevant studies based on independent title and abstract reading by the authors led to a final selection of 42 studies. They were carefully checked through abstract-reading with an outcome of seven studies fully meeting the inclusion criteria, which were selected for full-text reading and appraisal (Table 1). Excluded studies discussed the social aspects influencing medication rather than legal considerations in healthcare settings or had no exact relevance to patientsafety principles.

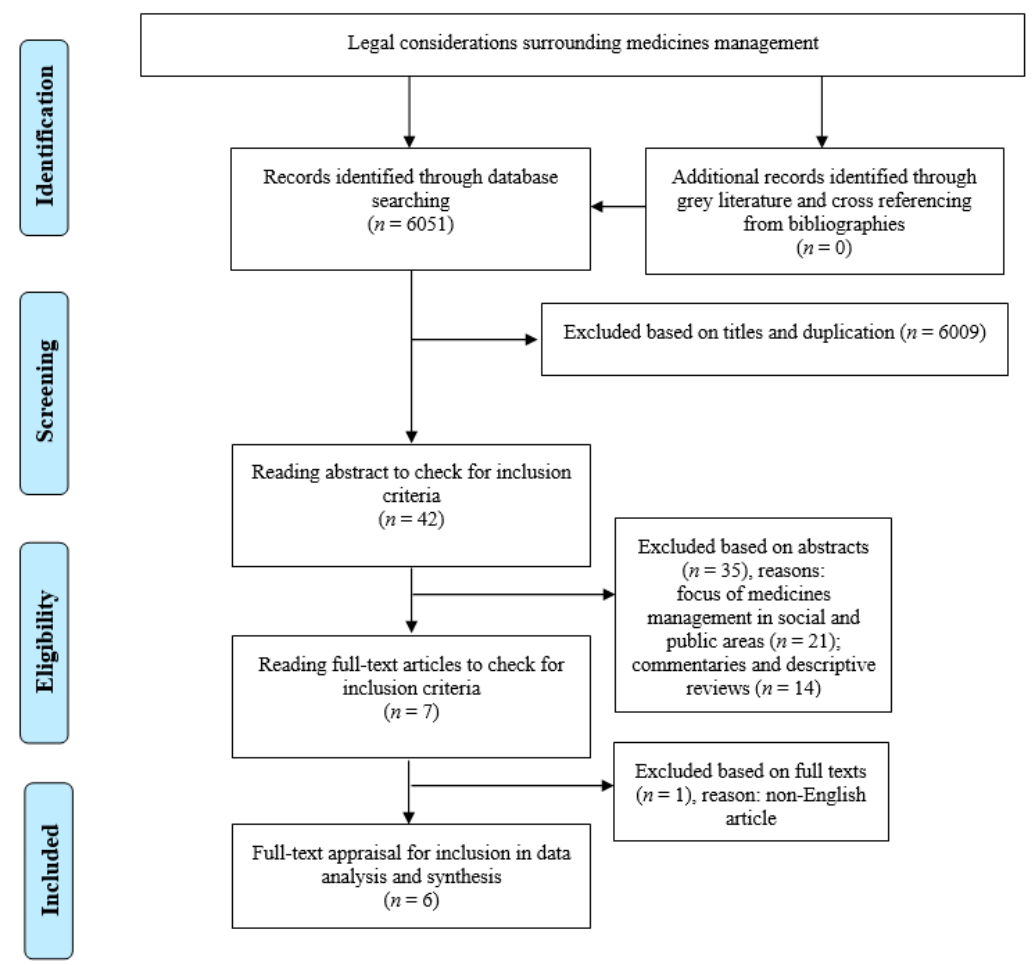

Figure 1. The process of the review adapted from the Preferred Reporting Items for Systematic Reviews and Meta-Analysis (PRISMA) [26]. The PRISMA Statement distributed under the terms of the Creative Commons Attribution License.

The full-texts were obtained from the Norwegian library and were carefully read in order to select only those studies with a precise focus on the legal considerations of medicines management and related factors in healthcare settings, and those with a highquality method in their research processes based on scores achieved using the appraisal tools. The full-text of one article was in French and was thus excluded, leaving six studies for full-text appraisal. The remaining articles $(n=6)$ were relevant to the review topic and had acceptable research structure and framework quality (Table 2). No further studies were found for inclusion during the grey literature and manual search in the reference lists of the selected studies. 
Table 1. The search strategy and results of different phases of the review.

\begin{tabular}{|c|c|c|c|c|c|}
\hline Keywords Used for Search & Databases from 2010-2020 & Total in Each Database & $\begin{array}{l}\text { Selection Based } \\
\text { on Title }\end{array}$ & $\begin{array}{l}\text { Selection Based on } \\
\text { Abstract }\end{array}$ & $\begin{array}{l}\text { Selection Based on } \\
\text { Full-Text Appraisal }\end{array}$ \\
\hline (medication OR drug OR medicines OR “pharmaceutical & PubMed (including Medline) & 2953 & 11 & 0 & 0 \\
\hline preparations" OR pharmaceuticals OR “medicines & Scopus & 1336 & 11 & 2 & 3 \\
\hline principle OR legislation OR Act OR guideline OR legal OR & Cinahl & 302 & 6 & 3 & 1 \\
\hline $\begin{array}{l}\text { bill OR convention OR policy OR obligation OR "breach of } \\
\text { duty" OR "legal duty" OR accountability OR responsibility }\end{array}$ & $\begin{array}{l}\text { Manual search/backtracking } \\
\text { references }\end{array}$ & 0 & 0 & 0 & 0 \\
\hline OR “patient's right" OR litigation OR duty) & Total of databases & 6051 & 42 & 7 & 6 \\
\hline
\end{tabular}

Table 2. Characteristics of selected studies for data analysis and synthesis.

\begin{tabular}{|c|c|c|c|c|c|c|}
\hline Author, Year, Country & Aim & Methods & Sample and Setting & Main Finding & Conclusion & $\begin{array}{c}\text { Full-Text } \\
\text { Appraisal Score }\end{array}$ \\
\hline $\begin{array}{l}\text { Craftman et al., 2013, } \\
\text { Sweden [27] }\end{array}$ & $\begin{array}{l}\text { To explore nurses' } \\
\text { perspectives on the } \\
\text { delegation of medicines } \\
\text { management to } \\
\text { unlicensed staff }\end{array}$ & $\begin{array}{l}\text { Descriptive } \\
\text { qualitative }\end{array}$ & $\begin{array}{l}20 \text { nurses in district } \\
\text { healthcare centres }\end{array}$ & $\begin{array}{l}\text { Incompatibility of delegation with } \\
\text { clinical practice; being in access to } \\
\text { home care providers }\end{array}$ & $\begin{array}{l}\text { Necessity of the } \\
\text { delegation of medicines } \\
\text { management and } \\
\text { difficulty in performing } \\
\text { the delegation task }\end{array}$ & 9 out of 10 \\
\hline $\begin{array}{l}\text { Duarte et al., 2015, } \\
\text { Portugal [28] }\end{array}$ & $\begin{array}{l}\text { To investigate ADRs } \\
\text { reporting and } \\
\text { knowledge of } \\
\text { pharmacovigilance } \\
\text { legislation among } \\
\text { pharmacists }\end{array}$ & $\begin{array}{l}\text { Mixed-methods } \\
\text { consisting of (i) } \\
\text { survey and (ii) focus } \\
\text { group interview }\end{array}$ & $\begin{array}{l}\text { (i) } 154 \text { pharmacists in the } \\
\text { south of country; (ii) } 7 \\
\text { community pharmacists }\end{array}$ & $\begin{array}{l}4965 \text { and } 5159 \text { reports in } 2005 \text { and } \\
2010 \text { were submitted, respectively: } \\
\text { (i) One-quarter were familiar with } \\
\text { ADRs reporting; (ii) } 38.3 \% \text { reported } \\
\text { ADRs, underreporting being due to } \\
\text { attitude issues and lack of } \\
\text { knowledge of casual relationship } \\
\text { between ADRs and medicines }\end{array}$ & $\begin{array}{l}\text { Need for education and } \\
\text { training }\end{array}$ & 14 out of 17 \\
\hline $\begin{array}{l}\text { Karlsen et al., 2015, } \\
\text { Sweden [29] }\end{array}$ & $\begin{array}{l}\text { To understand ADRs } \\
\text { reporting before and } \\
\text { after legislation changes } \\
\text { and the condition of } \\
\text { nurses' reporting }\end{array}$ & Cross-sectional & $\begin{array}{l}\text { Registered reports in six } \\
\text { regional centres for } \\
\text { handling spontaneous } \\
\text { ADRs reporting }\end{array}$ & $\begin{array}{c}898 \text { and } 1074 \text { reports to the } \\
\text { pharmacovigilance system in } 2005 \\
\text { and } 2010 \text {, respectively; } 31 \% \text { and } 24 \% \\
\text { of reports made by nurses in } \\
\text { these years }\end{array}$ & $\begin{array}{l}\text { Increase in the number } \\
\text { of serious/unlabelled } \\
\text { ADRs reports after } \\
\text { legislation }\end{array}$ & 22 out of 30 \\
\hline
\end{tabular}


Table 2. Cont.

\begin{tabular}{|c|c|c|c|c|c|c|}
\hline Author, Year, Country & Aim & Methods & Sample and Setting & Main Finding & Conclusion & $\begin{array}{c}\text { Full-Text } \\
\text { Appraisal Score }\end{array}$ \\
\hline $\begin{array}{l}\text { Bolcato et al., 2019, } \\
\text { Italy [30] }\end{array}$ & $\begin{array}{c}\text { To investigate } \\
\text { medico-legal litigation in } \\
\text { the management of } \\
\text { clinical risk and propose } \\
\text { a model }\end{array}$ & $\begin{array}{l}\text { Retrospective case } \\
\text { report }\end{array}$ & $\begin{array}{l}206 \text { cases of medico-legal } \\
\text { litigation settled in an } \\
\text { urban hospital from } \\
2014-2015\end{array}$ & $\begin{array}{l}20 \% \text { of the cases remained } \\
\text { unreported due to the latency } \\
\text { between the event and its } \\
\text { manifestations and discomfort } \\
\text { in reporting }\end{array}$ & $\begin{array}{l}\text { Need for the } \\
\text { establishment of a model } \\
\text { for rapid reporting }\end{array}$ & 6 out of 8 \\
\hline $\begin{array}{l}\text { Gøtzsche et al., 2019, } \\
\text { Denmark [31] }\end{array}$ & $\begin{array}{l}\text { To investigate if the law } \\
\text { and patients' rights were } \\
\text { respected when forced } \\
\text { medication orders were } \\
\text { appealed }\end{array}$ & $\begin{array}{l}\text { Retrospective case } \\
\text { report }\end{array}$ & $\begin{array}{l}30 \text { consecutive cases } \\
\text { registered on the } \\
\text { psychiatric appeals } \\
\text { board }\end{array}$ & $\begin{array}{l}\text { No clear indication of the suitability } \\
\text { of treatment to the patient's interest; } \\
\text { violation of the law on the use of } \\
\text { forced medications with the lowest } \\
\text { adverse effects }(97 \%)\end{array}$ & $\begin{array}{l}\text { Abandonment of forced } \\
\text { medication use }\end{array}$ & 6 out of 8 \\
\hline $\begin{array}{l}\text { Strickler et al., 2019, } \\
\text { USA [32] }\end{array}$ & $\begin{array}{l}\text { To examine the effect of } \\
\text { prescription drug } \\
\text { monitoring programs on } \\
\text { prescriber registration, } \\
\text { the programs' use and } \\
\text { prescription-based } \\
\text { measures of patient risk }\end{array}$ & $\begin{array}{c}\text { Cross-sectional } \\
\text { interrupted } \\
\text { time-series analyses }\end{array}$ & $\begin{array}{l}\text { Prescription and } \\
\text { prescriber usage of the } \\
\text { prescription drug } \\
\text { monitoring programs } \\
\text { from } 5 \text { states }\end{array}$ & $\begin{array}{l}\text { Legal mandates increased the } \\
\text { prescription and use of the } \\
\text { programs; reduction of the multiple } \\
\text { provider episode rate, opioid } \\
\text { prescribing and overlapping, } \\
\text { opioid/benzodiazepine } \\
\text { prescriptions' overlapping }\end{array}$ & $\begin{array}{l}\text { Reduction of risky } \\
\text { opioid prescriptions } \\
\text { through prescription } \\
\text { drug monitoring } \\
\text { programs' mandate }\end{array}$ & 24 out of 30 \\
\hline
\end{tabular}

ADRs: adverse drug reactions. 


\subsection{General Characteristics of the Selected Studies}

Table 2 provides an overview of the general characteristics of the selected studies for data analysis and synthesis. The studies were published between 2013 and 2019 and were conducted in Sweden [27,29], Portugal [28], Italy [30], Denmark [31] and USA [32].

There were variations in the studies' methods and research foci. One study comprised qualitative interviews focusing on nurses' perspectives of delegation of medicines management to unlicensed/ unregistered staff [27]; another was a mixed-methods study consisting of survey and focus groups with pharmacists regarding ADR reporting and knowledge of pharmacovigilance legislation [28]; two studies were retrospective case reports of medicolegal litigation and the management of clinical risk [30] and legal aspects of patients' rights in forced medication orders [31]; one was a cross-sectional study of ADR reporting before and after legislation changes and the conditions for nurse reporting [29] and another was a cross-sectional interrupted time-series analysis of prescription drug-monitoring programs and the related patient risk [32].

\subsection{Legal Considerations of Medicines Management}

The review findings were classified and grouped, based on the similarities and differences between the findings of the selected studies. The classification highlighted the legal considerations affecting medicines management in healthcare settings within the following categories developed by the authors: 'healthcare providers' education and monitoring tasks', 'individual and shared responsibility' and 'patients' rights'. They highlighted the interconnections of the legislation concerning medicines management, intended to improve the quality and safety of the medication process (Figure 2).

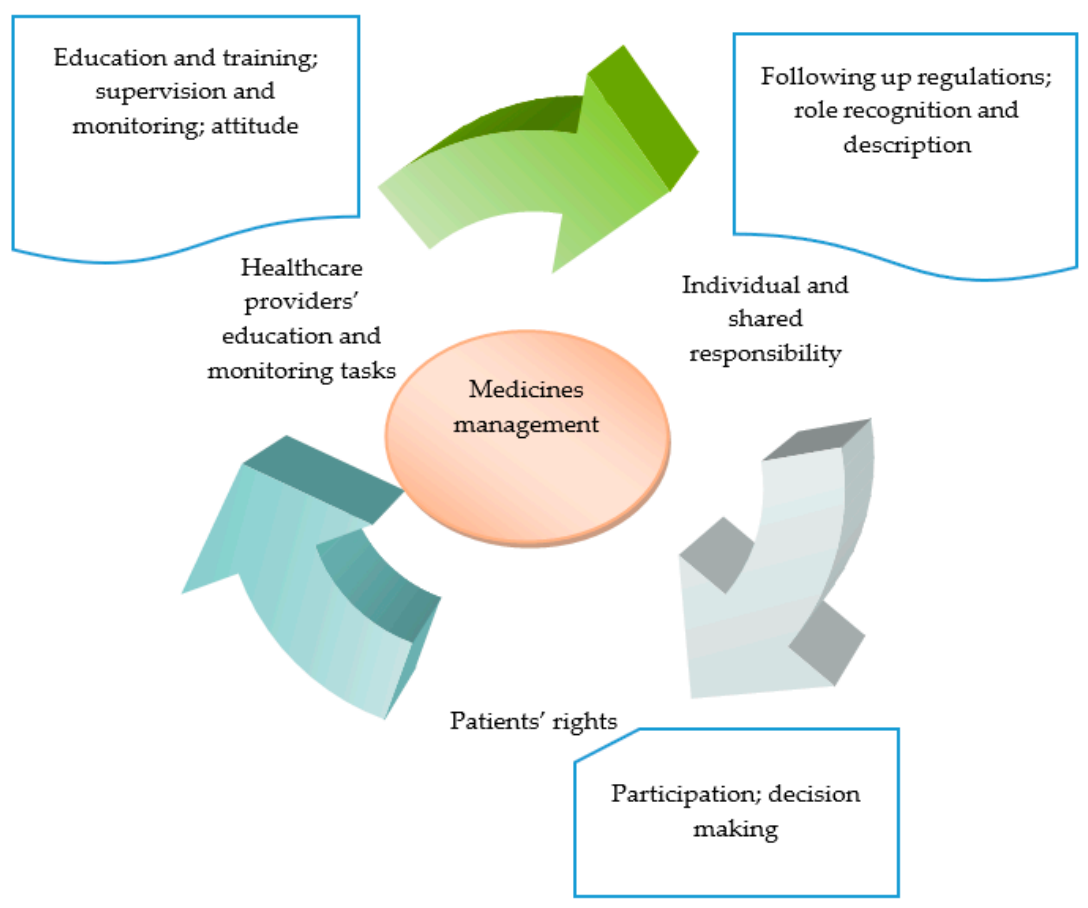

Figure 2. Categories developed regarding legal considerations surrounding medicines management.

Given these heterogeneities in the studies' methods, objectives and results, we presented the results of this review narratively under categories developed based on similarities and differences between the studies' findings. A summary of the studies' results has been presented in Table 3. 
Table 3. Summary of review findings based on the three categories evident.

\begin{tabular}{|c|c|c|c|}
\hline $\begin{array}{c}\text { Categories } \\
\text { Author, Year }\end{array}$ & $\begin{array}{c}\text { Healthcare Providers' } \\
\text { Education and Monitoring } \\
\text { Tasks }\end{array}$ & $\begin{array}{l}\text { Individual and Shared } \\
\text { Responsibility }\end{array}$ & Patients' Rights \\
\hline Craftman et al., 2013 [27] & $\begin{array}{l}\text { Supervision, education and } \\
\text { training regarding medication } \\
\text { preparation and } \\
\text { administration; validated } \\
\text { guidelines and tools }\end{array}$ & $\begin{array}{l}\text { Difficulty in following up } \\
\text { regulations; recognition of the } \\
\text { nurse's role }\end{array}$ & No data \\
\hline Duarte et al., 2015 [28] & $\begin{array}{l}\text { Being informed and educated } \\
\text { about pharmacovigilance; } \\
\text { attitudes towards reporting }\end{array}$ & $\begin{array}{l}\text { Difficulty in the process of } \\
\text { reporting medicines' side } \\
\text { effects/ADRs; recognition of } \\
\text { professionals'/employees' } \\
\text { roles }\end{array}$ & No data \\
\hline Karlsen et al., 2015 [29] & $\begin{array}{l}\text { Legislative support for } \\
\text { reporting medication side } \\
\text { effects and ADRs }\end{array}$ & Recognition of the nurse's role & No data \\
\hline Bolcato et al., 2019 [30] & No data & No data & $\begin{array}{c}\text { Sentinel medication errors, } \\
\text { their detection and } \\
\text { compensation; }\end{array}$ \\
\hline Gøtzsche et al., 2019 [31] & No data & No data & $\begin{array}{l}\text { Patient participation, decision } \\
\text { making for prescription and } \\
\text { administration }\end{array}$ \\
\hline Strickler et al., 2019 [32] & $\begin{array}{l}\text { The use of the electronic } \\
\text { health record system; } \\
\text { customising the law }\end{array}$ & No data & No data \\
\hline
\end{tabular}

ADRs: adverse drug reactions.

\subsubsection{Healthcare Providers' Education and Monitoring Tasks}

A series of measures to support the lawful practice of medicines management including the education of healthcare staff and the application of monitoring tools was needed to guarantee the implementation of regulations and rules determined by legislation, with the aim of ensuring safe medicines management.

The education and empowerment of healthcare professionals was emphasised, based on findings that healthcare staff frequently lacked knowledge and skills regarding medicines management and its legal aspects.

Craftman et al., concluded delegation of medicines management to unlicensed healthcare staff could be lawful following sufficient education and training to prevent medication errors. Also, nurses who gained their knowledge of medicines management through practical and on-the-job training, rather than formal education, were identified as needing education and supervision to prevent errors during the preparation of medicines, mixing medicines, and crushing tablets before administration [27].

Duarte et al. indicated that not all pharmacists $(70 \%)$ knew about the new pharmacovigilance legislation supporting the reporting of ADRs and side effects. Some lacked sufficient knowledge on the new definition of ADRs or lacked positive attitudes towards checking details on the relevant websites to be able to report suspected ADRs. Therefore, knowledge development in pharmacovigilance, clinical pharmacology and attribution of causality for medicines' side effects and ADRs seemed necessary [28].

Legally enforced and standardised monitoring tools would ensure reporting medicines' side effects and ADRs.

Karlsen et al., stated that before the passing of legislation supporting ADRs reporting in 2005, only 100 reports were submitted (ever), compared with 172 reports after legislation came into effect in 2010, and its implementation was monitored and supported [29].

According to Strickler et al., legal sanctions that addressed over-prescription and risky opioid use, together with the implementation of monitoring programs for the prescription 
of medicines, encouraged prescribers to actively follow medicines management guidelines and ensure the safety of medication through efforts to customize the law and suit it to cultural contexts that improved its effectiveness. The review and registration of the patient's prescription history as a monitoring tool before prescribing opioids was mandated. This reduced multiple prescribing, the opioid prescribing rate, overlapping opioid prescriptions, and overlapping opioid/benzodiazepine prescriptions [32].

From the perspective of Craftman et al., standardised methods for the delegation of medicines management consisting of validated tools and guidelines were key to assess healthcare staff's readiness for assuming responsibility for medication and risk management under the supervision of a licensed nurse [27]. Also, Strickler et al., believed that the use of the electronic health record system and customising the law to suit the care context in terms of staffing pattern and equipment helped with monitoring the medication process and reducing the risk of medication errors, and guaranteed the implementation of legal initiatives of medicines management [32].

\subsubsection{Individual and Shared Responsibility}

The success of legal initiatives supporting medicines management depended on the creation of a sense of both individual and shared responsibility for the accurate implementation of the law. Legislation and enforcement actions could not guarantee adherence to medicines management guidelines. Legal initiatives alone were insufficient: shared motivation and responsibility were needed.

Craftman et al. reported that difficulties in following rules and regulations for delegating medication duties to unlicensed healthcare staff, combined with incompatibility between the regulations and current practice, detracted from individual responsibility. In general, regulations and guidelines were outdated and did not consider staff shortages, heavy workloads and transitional care from healthcare settings to patients' own homes, causing a disconnect with current practice and changes [27]. In Duarte et al., whilst $66 \%$ of pharmacists were willing to report ADRs, difficulties related to the process of reporting, including malfunctioning websites and complicated and long reporting forms, were barriers to individual responsibility for reporting [28].

Duarte et al. defined shared responsibility for medicines management in terms of reporting and publishing reports of medicines' side effects and ADRs by the entire chain of stakeholders, from the pharmaceutical industry to healthcare settings. Legislation should recognise the role of each healthcare worker and describe how each role is responsible for safe medicines management [28]. Craftman et al. also stated that the duty of the delegation of medication by nurses to other healthcare staff should be legally recognised and supported in order to prevent interference in other healthcare staff's responsibilities and damaging their feeling of accountability for medicines management in community settings [27]. Karlsen et al., found that after the introduction of legislation on reporting ADRs in 2010, physicians more often reported (75\%) than nurses (24\%). Reporting of serious ADRs stood at $3-7 \%$ and $48-49 \%$ by nurses and physicians, respectively. These reports were mostly related to systemic antibiotics, vaccines and antivirals, nervous system drugs, contrast media, and respiratory medications. The reduction in the number of ADR reports by nurses after legislation introduction was attributed to inappropriate definition of nurses' roles in ADR reporting and restriction of their scope of practice in reporting ADRs to a narrow subset of medications. The close contact between nurses and patients and their general responsibility for medicines administration and assessment of their outcomes in hospitalised patients highlighted nurses' valuable role in improving pharmacovigilance, but this role was not clearly specified in law and so failed to support nurses as ADR reporters [29].

\subsubsection{Patients' Rights}

Medication practice with appropriate legal oversight supported patients' rights through: selection of the most effective medicines with the lowest risks of adverse side effects, patient 
participation as the provision of choice between medications and information on probable side effects and adverse reactions.

Bolcato et al. stated that sentinel cases of medication errors are unanticipated events, unrelated to the patient's underlying health condition, resulting in death or serious physical or psychological damage. Sentinel medication errors during a 2-year period arising in the course of medicines management had legal consequences, including compensation. Events included: botulinum injection during surgery for mild equinism on the wrong foot; no prescription of low molecular weight heparin after cardiac surgery followed by massive pulmonary embolism; and frequent intra-detrusoral infiltration of botulinum for recurrent cystitis, followed by bladder dysfunction and sexual impairment, of which eight cases were compensated and 15 cases were under treatment [30].

Gøtzsche et al. highlighted the issues of ignoring the law and patients' rights during the medication process: 30 consecutive appeals over the forced use of mental health medicines were reported. They included: failure to assess patients' medical files, absence of expert consultation regarding the necessity of prescriptions, selection of medicines with the highest risks of adverse effects (olanzapine, risperidone, zuclopenthixol, paliperidone, quetiapine, aripiprazole), injection, rather than oral administration, exceeding the manufacturers' recommended doses, failure to attempt patient participation and motivate the patient to accept treatment voluntarily before forced use, and lack of documentation for forced prescriptions and the patient's inability to give informed consent [31].

\section{Discussion}

This systematic review, through integrating the findings of empirical qualitative and quantitative studies, augments our knowledge regarding the legal considerations for medicines management in healthcare settings.

Measures to guarantee the implementation of legal initiatives and regulations for safe medicines management depended on the education of healthcare staff and monitoring the implementation of safety regulations. Unmet educational needs in pharmacology and medicines management, as well as ineffective evaluation of medication practice, represent common issues affecting patient safety across healthcare disciplines [33]. Knowledge of the law and legal considerations surrounding medicines management is often under-represented in healthcare curricula [34]. However, the development of medicines management competencies requires appropriate clinical education and supervision $[35,36]$ and should encompass the appropriate use of standard checklists and the development of action plans to remove the gap between policymaking and implementation in practice [37]. Standardised safe medication checklists as monitoring tools have been proven to be effective in preventing lapses and reducing the incidence of adverse events by ensuring the implementation of the law and adherence to related guidelines [38].

This review highlighted the need for standardised tools to guide the implementation of legal initiatives and facilitate the participation of healthcare providers and patients in medicines management. Structures and processes that standardise care are key to preventing medication errors [39]. Surveillance systems should encompass all aspects of the medication cycle, including prescribing, distribution, administration and monitoring [40]. Systematized, formal and documented processes help to identify and address medication errors and adverse events while they are still containable, and before harm occurs to patients $[19,41]$. Risk assessment tools and corresponding standards, and/or national guidelines for monitoring and handling certain high-risk medications increase the safety of administration, and similar process should be applied to encourage reporting of errors $[42,43]$.

Our review indicates that reporting of ADRs is suboptimal and would be improved by a more robust legal framework. An ADR is an unintended and harmful reaction in the patient to a medicine associated with any administered dose, which can lead to lifethreatening conditions, persistent disability, hospitalization, and even a patient's death $[44,45]$. Under-reporting of ADRs has been attributed to limited knowledge among healthcare 
providers and limited durability of related educational interventions [46]. Additionally, poor awareness of the risks of under-reporting, particularly underestimation of these risks, inappropriate reporting tools, delayed or no feedback on reported ADRs, and fear of legal liability have been mentioned as common barriers to reporting ADRs [47]. Most reporting systems and electronic medical records contain no specific category for ADRs [48]. Training activities to rationally prescribe, distribute, and monitor medications with close followup for adverse reactions, and reporting mechanisms, are the main steps to improving pharmacovigilance [49-51]. Although national error reporting systems exist in many countries, the number of ADRs reported remains low and the quality of reports is often poor $[19,48]$. An intervention programme using the incorporation of legal aspects of medicines management and education via posters, lectures and electronic distance learning can enhance the knowledge and attitudes of caregivers towards reporting [19,52,53].

According to the review findings, the prescription and administration of medications should be directly addressed by the law. The presence of the law unifies the area of accountability among healthcare providers, allowing patients to benefit from medicines' therapeutic effects as well as protecting them against medications' harmful effects [53]. Clear laws and regulations for medicines management are the required underpinnings for clinical practice guidelines, which support safe and effective handling of medicines by healthcare providers [54]. Medication errors happen often when healthcare providers have insufficient knowledge about rules, modify rules or do not follow them in full [55]. Therefore, regular education to update knowledge and understanding of the medicolegal aspects of patient care is required to ensure quality of care [56]. All healthcare professionals have a duty to follow rules and regulations for safe medication practice. If these cannot be followed because of systemic deficiencies, professionals are obliged to report system shortcomings and suggest remedies [57]. It is thus the responsibility of healthcare managers to ensure that safety systems are in place and to ensure patient safety through the consideration of legal, regulatory, ethical, humanistic and practical considerations in addressing medication adverse events [58].

Incorporating medicines management programs into the electronic health record system was found to be important. Structured medication interventions using computerized decision support systems improves the appropriateness and accuracy of medication regimens among hospitalized patients [59]. In spite of current shortcomings in updated protocols for new medications, the use of electronic systems for medication prescription may improve patient safety through enhancing interprofessional communication and accountability [60]. For example, the use of digital devices that remind patients to take a pill, verify the actual intake, and collect and send related data to a remote computer system have been helpful. However, this raises questions about patients' rights to autonomy and potentially violates privacy rights through the secondary use of patient data and healthcare providers' data, which has implications for liability [61,62].

According to this review, individual and shared responsibility were required for the successful implementation of legal initiatives supporting medicines management. However, barriers to shared responsibilities included: the lack of knowledge of ADRs and reporting systems, incompatibility between the law and the healthcare context, and lack of recognition of healthcare staff roles in medicines management. While there is no consensus about which healthcare profession is most suited to medicines management roles, it is accepted that trained and competent staff should assume these critical roles $[63,64]$. Shared decision making as a means of acknowledging power differentials and providing information about medicines should be routine in all areas of health care, but this aspect of medicines management is under-represented in existing literature [65]. Since medication errors involve different healthcare professionals, a collaborative approach, especially among vulnerable patients, has been suggested [66]. Collaboration through communication, sharing information and the provision of regular feedback can improve adherence to the principles of safe medication practice [39]. Nurses have the required knowledge and skills regarding medicines management and spend more time with patients than 
physicians and pharmacists, increasing their chances of detecting medicines discrepancies and near misses [67-69]. Therefore, nurses' role, accountability and knowledge of medications should be taken into account when strategies are devised to improve medicines management $[19,66,70]$.

In our review the law should support how to detect near misses and medication errors with a sentinel identity, help prevent patient harm and reduce its impact on patients. Medication errors with serious consequences for the patient health often remain underreported [71]. Disclosing medication errors through the regular use of audit and failure mode, effect, and criticality analysis (FMECA) improves the performance of individuals and the reliability of healthcare systems [72]. Learning from near misses and errors improves the culture of safety $[66,73]$.

Medication practice should consider patients' rights through the prescription of medicines with the fewest side effects, and patient participation by informing them of all possible adverse or undesirable effects. Patients' health and well-being depend on collaboration between patients and healthcare providers in a respectful alliance. Healthcare providers serve patients as their advocates and respect their rights by providing them with the decision-making capacity to be able to accept or refuse recommended medications [74]. Disguising medicines in food or drink is a common practice (43-71\%) in the majority of nursing homes [75] and is accompanied with incomplete documentation and consultation with patients' representatives or other healthcare providers, contravening the law [75,76]. The preservation of patients' rights in the contemporary healthcare system is more complicated than the linear process of medication administration and should consider the whole process of medicines management $[77,78]$. Patients' rights should encompass the discussion of specific risks and benefits of proposed therapy with patients or their guardians and the documentation of informed consent to medicine administration in the medical record [79].

Limitations of this review include the heterogeneity of the selected studies' methods and variations in their focus, which could impact the integration of the findings. A thorough search process using multidimensional keywords applied commonly in the field of healthcare was performed in international databases, but a few empirical studies were retrieved, indicating a paucity of research on this important aspect of patient safety. Despite the possibility of unintentional oversight by the authors in identifying all relevant keywords for the search, the review provides a contemporary overview of the legal considerations of medicines management as well as offering leads regarding aspects in need of further elaboration in future studies.

\section{Conclusions}

The findings of this review identified significant individual and system factors regarding the legal considerations of medicines management in the healthcare system. A summary of the review findings and suggested improvement strategies has been presented in Table 4. 
Table 4. Improvement strategies based on the review findings.

Categories Areas of Interest

Insufficient knowledge and skills regarding medicines management, particularly amongst unlicensed healthcare staff

Lack of knowledge of and negative attitudes towards pharmacovigilance legislation

Healthcare providers' education and monitoring tasks

Effectiveness of legal monitoring guidelines to reduce medicines'
over-prescription and risky use

Highlighting the role of electronic health record systems

Difficulties in following rules and regulations
Improvement Strategies

Education and training regarding medicines preparation and administration;

Direct supervision to ensure medicines management competencies

Education on legislation influencing medicines management; Improvement of culture surrounding patient safety;

Development of knowledge about the causes of medicines' side effects and ADRs

Application of standardised and contextually adapted checklists for safe medication practice

Use of monitoring tools by healthcare leaders to monitor healthcare staff skills and healthcare environment to reduce errors and manage risks

Application of electronic health record systems for the communication and documentation of the medication process;

Use of computerized medication decision support systems
Improvement of working conditions;

Development of structured surveillance systems for prescribing, administration, and monitoring

Importance of individual motivation to follow regulations

Supporting ADR reporting and following up medicines management guidelines

Individual and shared responsibility

Significance of healthcare provider's roles and mutual reasonability towards safe medication practice

Education and training regarding the professional roles and duties of healthcare staff;

Development of cultures of shared decision making;

Collaboration through communication and mutual feedback;

Clear task assignment and job description emphasising mutual responsibility towards safe medicines management

Need for the detection, reporting of sentinel medication errors and their appropriate compensation

Patients' rights

Highlighting patients' participation throughout the medication process
Use of active error detection methods, analysis of and learning from potential medication errors

Informing the patient about risks and benefits of medicines; Inviting the patient to be involved in decision making regarding the selection of medicine

ADRs: adverse drug reactions. 
These findings can be used for developing a framework of action to improve the safety of medicines management and avoid legal issues affecting both the healthcare provider and the patient.

Author Contributions: The authors contributed to the design and implementation of the research, to the analysis of the results and to the writing of the manuscript as follows; M.V., S.J., S.A. \& M.G.: Conceptualization, Data curation, Formal analysis, Investigation, Methodology, Project administration, Resources, Software; M.V., S.J., P.A.L. \& M.G., Writing-original draft, Writing-review and editing. All authors have read and agreed to the published version of the manuscript.

Funding: This research received no external funding.

Institutional Review Board Statement: Not applicable.

Informed Consent Statement: Not applicable.

Data Availability Statement: All data is contained within the article.

Acknowledgments: Nord University, Bodø, Norway covered the processing charge to this article.

Conflicts of Interest: The authors declare no conflict of interest.

\section{Appendix A}

Table A1. The protocol for the systematic review of legal considerations surrounding medicines management in healthcare settings.

Aspects and Definitions $\quad$ Practical Notes

Identification of the research question

A systematic review on legal considerations of medicines management in healthcare settings

An integrative systematic review English

All original research-based studies
Legal considerations and strategies to ensure patient safety through safe medicines management influencing on the quality care in the healthcare system.

$\begin{array}{cc}\text { Review type } & \text { An integrative systematic } \\ \text { review } \\ \text { Language } & \text { English } \\ \text { Study designs } & \text { All original research-based } \\ & \text { studies }\end{array}$

Literature search
Researcher(s)

Databases

Manual search and grey literature

\begin{tabular}{c} 
Researcher(s) \\
\hline Databases \\
Manual search and grey \\
literature
\end{tabular}

Keywords
Both qualitative and quantitative studies will be considered. Studies will be experimental, cross-sectional, qualitative, but reviews, commentaries, letters, and books will be excluded.

An international team of researchers working on medicines management.

Electronic databases such as Scopus, PubMed [including Medline], Cinahl, Web of Science for retrieving studies published from 2010 to 2020.

Important journals for manual search will be identified during the references checking of retrieved articles selected for full-text appraisal.

Grey literature includes policy documents, clinical guidelines, and cross-references from bibliographies for improving the search coverage.

After a pilot search in databases, keywords for search to be used via the Boolean Method are as follows:

(medication OR drug OR medicines OR "pharmaceutical preparations" OR pharmaceuticals OR "medicines management") AND (law OR rule OR regulation OR principle OR legislation OR Act OR guideline OR legal OR bill OR convention OR policy OR obligation OR "breach of duty" OR "legal duty" OR accountability OR responsibility OR "patient's right" OR litigation OR duty). 
Table A1. Cont.

\begin{tabular}{|c|c|c|}
\hline \multicolumn{2}{|c|}{ Aspects and Definitions } & Practical Notes \\
\hline \multirow{3}{*}{ Literature selection } & $\begin{array}{c}\text { Selecting original studies in } \\
\text { stages }\end{array}$ & Based on titles, abstracts and full texts of articles. \\
\hline & $\begin{array}{l}\text { Pre-tested inclusion criteria for } \\
\text { original studies }\end{array}$ & $\begin{array}{l}\text { Explicit interest to the study topic; original and scientific } \\
\text { content related to the study topic; focused on the legal } \\
\text { considerations of medicines management in clinical practice } \\
\text { in short-term and long-term healthcare settings and } \\
\text { published in online peer-reviewed scientific journals. } \\
\text { Articles without an exact relevance on legal aspects and } \\
\text { considerations of medicines management in clinical practice } \\
\text { will be excluded. }\end{array}$ \\
\hline & Quality criteria & $\begin{array}{l}\text { Methodological checklists for full-text appraisals can be } \\
\text { found at: } \\
\text { https:/ / www.equator-network.org/ }\end{array}$ \\
\hline Equator guidelines & PRISMA & $\begin{array}{l}\text { The whole process of review will be assessed using the } \\
\text { methodological checklist of systematic reviews and } \\
\text { meta-analyses developed by the http: } \\
\text { / / prisma-statement.org/prismastatement/Checklist.aspx }\end{array}$ \\
\hline
\end{tabular}

PRISMA: Preferred Reporting Items Systematic Reviews and Meta-Analysis.

\section{References}

1. Nabhan, M.; Elraiyah, T.; Brown, D.R.; Dilling, J.A.; Leblanc, A.; Montori, V.M.; Morgenthaler, T.I.; Naessens, J.M.; Prokop, L.J.; Roger, V.L.; et al. What is preventable harm in healthcare? A systematic review of definitions. BMC Health Serv. Res. 2012, 12, 128. [CrossRef] [PubMed]

2. Runciman, W.B.; Merry, A.F.; Tito, F. Error, blame, and the law in health care-An antipodean perspective. Ann. Intern. Med. 2003, 138, 974-979. [CrossRef] [PubMed]

3. Guillod, O. Medical error disclosure and patient safety: Legal aspects. J. Public Health Res. 2013, 2, e31. [CrossRef] [PubMed]

4. World Health Organization (WHO). Conceptual Framework for the International Classification for Patient Safety Version 1.1. 2010. Available online: https:/ / www.who.int/patientsafety/implementation/taxonomy/ICPS-report/en/ (accessed on 15 June 2020).

5. World Health Organization (WHO). Patient Safety: Making Health Care Safer. 2017. Available online: https://apps.who.int/iris/ handle/10665/255507 (accessed on 15 June 2020).

6. Schwendimann, R.; Blatter, C.; Dhaini, S.R.; Simon, M.; Ausserhofer, D. The occurrence, types, consequences and preventability of in-hospital adverse events-A scoping review. BMC Health Serv. Res. 2018, 18, 521. [CrossRef]

7. Light, D.W.; Lexchin, J.; Darrow, J.J. Institutional Corruption of Pharmaceuticals and the Myth of Safe and Effective Drugs. J. Law Med. Ethics 2013, 41, 590-600. [CrossRef]

8. World Health Organization (WHO). Patient Safety. 2020. Available online: https://www.who.int/patientsafety/en/ (accessed on 9 June 2020).

9. Donaldson, L.J.; Fletcher, M.G. The WHO World Alliance for Patient Safety: Towards the years of living less dangerously. Med. J. Aust. 2006, 184, S69-S72. [CrossRef]

10. European Commission. Pharmaceutical Package. 2008. Available online: https://ec.europa.eu/health/human-use/package_en (accessed on 8 June 2020).

11. European Commission. Patient Safety-Making It Happen! Luxembourg Declaration on Patient Safety. Luxembourg European Commission, DG Health and Consumer Protection. 2005. Available online: https:/ / ec.europa.eu/health/ph_overview/Documents/ ev_20050405_rd01_en.pdf (accessed on 9 June 2020).

12. International Council of Nurses (ICN). Patient Safety. 2020. Available online: https://www.icn.ch/nursing-policy/icn-strategicpriorities/ patient-safety (accessed on 17 February 2020).

13. Deslandes, P.; Pitcher, B.; Young, S. Medicines Management. Learning to Care: The Nursing Associate; Elsevier: Edinburgh, UK, 2019.

14. Organisation for Economic Cooperation and Development (OCED). Health at a Glance 2019-OECD Indicators. 2019. Available online: https: / / doi.org/10.1787/4dd50c09-en (accessed on 15 June 2020).

15. World Health Organization (WHO). Human Rights and Health. 2017. Available online: https://www.who.int/news-room/factsheets/detail/human-rights-and-health (accessed on 9 June 2020).

16. Council of Europe. Committee of Experts on Management of Safety and Quality in Health Care (SP-SQS) Expert Group on Safe Medication Practices Glossary of Terms Related to Patient and Medication Safety. 2005. Available online: https: / / www.who.int/patientsafety/highlights/COE_patient_and_medication_safety_gl.pdf (accessed on 16 November 2020).

17. Food and Drug Administration (FDA). FDA Organization. 2020. Available online: https://www.fda.gov/about-fda/fdaorganization (accessed on 8 June 2020). 
18. Patel, K.; Jay, R.; Shahzad, M.W.; Green, W.; Patel, R. A systematic review of approaches for calculating the cost of medication errors. Eur. J. Hosp. Pharm. 2016, 23, 294-301. [CrossRef]

19. Jordan, S.; Logan, P.A.; Panes, G.; Vaismoradi, M.; Hughes, D. Adverse Drug Reactions, Power, Harm Reduction, Regulation and the ADRe Profiles. Pharmacy 2018, 6, 102. [CrossRef]

20. Higgins, J.P.T.; Green, S. Cochrane Handbook for Systematic Reviews of Interventions. Version 5.1. 2011. Available online: http:/ / handbook-5-1.cochrane.org/ (accessed on 21 May 2020).

21. Thomas, J.; Harden, A.; Oakley, A.; Oliver, S.; Sutcliffe, K.; Rees, R.; Brunton, G.; Kavanagh, J. Integrating qualitative research with trials in systematic reviews. BMJ 2004, 328, 1010-1012. [CrossRef]

22. Strengthening the Reporting of Observational Studies (STROBE). 2009. Available online: https:/ /www.strobe-statement.org/ index.php?id=available-checklists (accessed on 20 October 2020).

23. Critical Appraisal Skills Programme (CASP), Qualitative Checklist. 2018. Available online: https://casp-uk.net/wp-content/ uploads/2018/01/CASP-Qualitative-Checklist-2018.pdf (accessed on 20 October 2020).

24. Mixed Methods Appraisal Tool (MMAT). 2018. Available online: http://mixedmethodsappraisaltoolpublic.pbworks.com/w / page/24607821/FrontPage (accessed on 20 October 2020).

25. Moola, S.; Munn, Z.; Tufanaru, C.; Aromataris, E.; Sears, K.; Sfetc, R.; Currie, M.; Lisy, K.; Qureshi, R.; Mattis, P.; et al. Chapter 7: Systematic Reviews of Etiology and Risk. JBI Man. Evid. Synth. 2020. [CrossRef]

26. Liberati, A.; Altman, D.G.; Tetzlaff, J.; Mulrow, C.; Gøtzsche, P.C.; Ioannidis, J.P.A.; Clarke, M.; Devereaux, P.J.; Kleijnen, J.; Moher, D. The PRISMA statement for reporting systematic reviews and meta-analyses of studies that evaluate healthcare interventions: Explanation and elaboration. BMJ 2009, 339, b2700. [CrossRef]

27. Craftman, A.G.; Von Strauss, E.; Rudberg, S.L.; Westerbotn, M. District nurses' perceptions of the concept of delegating administration of medication to home care aides working in the municipality: A discrepancy between legal regulations and practice. J. Clin. Nurs. 2013, 22, 569-578. [CrossRef]

28. Duarte, M.; Ferreira, P.; Soares, M.; Cavaco, A.M.; Martins, A.P. Community pharmacists' attitudes towards adverse drug reaction reporting and their knowledge of the new pharmacovigilance legislation in the southern region of Portugal: A mixed methods study. Drugs Ther. Perspect. 2015, 31, 316-322. [CrossRef]

29. Karlsson, S.A.; Jacobsson, I.; Boman, M.D.; Hakkarainen, K.M.; Lövborg, H.; Hägg, S.; Jönsson, A.K. The impact of a changed legislation on reporting of adverse drug reactions in Sweden, with focus on nurses' reporting. Eur. J. Clin. Pharmacol. 2015, 71, 631-636. [CrossRef] [PubMed]

30. Bolcato, M.; Fassina, G.; Rodriguez, D.; Russo, M.; Aprile, A. The contribution of legal medicine in clinical risk management. BMC Health Serv. Res. 2019, 19, 1-6. [CrossRef] [PubMed]

31. Gøtzsche, P.C.; Vinther, S.; Sørensen, A. Forced medication in psychiatry: Patients' rights and the law not respected by appeals board in Denmark. Clin. Neuropsychiatry 2019, 16, 229-233. [CrossRef]

32. Strickler, G.K.; Zhang, K.; Halpin, J.F.; Bohnert, A.S.; Baldwin, G.T.; Kreiner, P.W. Effects of mandatory prescription drug monitoring program (PDMP) use laws on prescriber registration and use and on risky prescribing. Drug Alcohol Depend. 2019, 199, 1-9. [CrossRef]

33. Stenner, K.; Edwards, J.; Mold, F.; Otter, S.; Courtenay, M.; Moore, A.; Carey, N. Medicines management activity with physiotherapy and podiatry: A systematic mixed studies review. Health Policy 2018, 122, 1333-1339. [CrossRef]

34. Kapp, M.B. Teaching legal competencies through an individualized elective in medicine and law. Gerontol. Geriatr. Educ. 2018, 39, 491-494. [CrossRef] [PubMed]

35. Biddison, E.L.D.; Paine, L.; Murakami, P.; Herzke, C.; Weaver, S.J. Associations between safety culture and employee engagement over time: A retrospective analysis. BMJ Qual. Saf. 2016, 25, 31-37. [CrossRef] [PubMed]

36. Pront, L.; Gillham, D.; Schuwirth, L.W.T. Competencies to enable learning-focused clinical supervision: A thematic analysis of the literature. Med. Educ. 2016, 50, 485-495. [CrossRef] [PubMed]

37. Agoro, O.O.; Osuga, B.O.; Adoyo, M. Supportive supervision for medicines management in government health facilities in Kiambu County, Kenya: A health workers' perspective. Pan Afr. Med. J. 2015, 20, 237. [CrossRef] [PubMed]

38. Thomassen, Ø.; Storesund, A.; Søfteland, E.; Brattebø, G. The effects of safety checklists in medicine: A systematic review. Acta Anaesthesiol. Scand. 2014, 58, 5-18. [CrossRef] [PubMed]

39. Vaismoradi, M.; Tella, S.; Logan, P.A.; Khakurel, J.; Vizcaya-Moreno, F. Nurses' Adherence to Patient Safety Principles: A Systematic Review. Int. J. Environ. Res. Public Health 2020, 17, 2028. [CrossRef] [PubMed]

40. Kane-Gill, S.L.; Dasta, J.F.; Buckley, M.S.; Devabhakthuni, S.; Liu, M.; Cohen, H.; George, E.L.; Pohlman, A.S.; Agarwal, S.; Henneman, E.A.; et al. Clinical Practice Guideline: Safe Medication Use in the ICU. Crit. Care Med. 2017, 45, e877-e915. [CrossRef] [PubMed]

41. Jordan, S.; Banner, T.; Gabe-Walters, M.; Mikhail, J.M.; Panes, G.; Round, J.; Snelgrove, S.; Storey, M.; Hughes, D. Nurse-led medicines' monitoring in care homes, implementing the Adverse Drug Reaction (ADRe) Profile improvement initiative for mental health medicines: An observational and interview study. PLoS ONE 2019, 14, e0220885. [CrossRef]

42. Halpern, K.J.; McKinnon, R.; Okolo, A.N.; Sanzio, T.M.; Dolan, C. A Medication Error and Legislation Designed to Punish: The American Association of Nurse Attorneys Defends Just Culture in Nursing. J. Nurse Pract. 2016, 12, 109-112. [CrossRef]

43. Kellett, P.; Gottwald, M. Double-checking high-risk medications in acute settings: A safer process. Nurs. Manag. 2015, 21, 16-22. [CrossRef] 
44. Coleman, J.J.; Pontefract, S.K. Adverse drug reactions. Clin. Med. 2016, 16, 481-485. [CrossRef]

45. World Health Organization (WHO). Safety of Medicines: A Guide to Detecting and Reporting Adverse Drug Reactions-Why Health Professionals Need to Take Action. 2002. Available online: http://archives.who.int/tbs/safety/esd_safety.pdf (accessed on 12 June 2020).

46. Güner, M.D.; Ekmekci, P.E. Healthcare professionals' pharmacovigilance knowledge and adverse drug reaction reporting behavior and factors determining the reporting rates. J. Drug Assess. 2019, 8, 13-20. [CrossRef]

47. Nadew, S.S.; Beyene, K.G.; Beza, S.W. Adverse drug reaction reporting practice and associated factors among medical doctors in government hospitals in Addis Ababa, Ethiopia. PLoS ONE 2020, 15, e0227712. [CrossRef] [PubMed]

48. Thomas, R.E.; Nguyen, L.T.; Jackson, D.; Naugler, C. Potentially Inappropriate Prescribing and Potential Prescribing Omissions in 82,935 Older Hospitalised Adults: Association with Hospital Readmission and Mortality within Six Months. Geriatrics 2020, 5, 37. [CrossRef]

49. Elnour, A.A.; Ahmed, A.D.; Yousif, M.A.E.; Shehab, A. Awareness and Reporting of Adverse Drug Reactions among Health Care Professionals in Sudan. Jt. Comm. J. Qual. Patient Saf. 2009, 35, 324-329. [CrossRef]

50. Alemu, B.K.; Biru, T.T. Health Care Professionals' Knowledge, Attitude, and Practice towards Adverse Drug Reaction Reporting and Associated Factors at Selected Public Hospitals in Northeast Ethiopia: A Cross-Sectional Study. BioMed Res. Int. 2019, 2019, 8690546. [CrossRef]

51. Reumerman, M.O.; Tichelaar, J.; Piersma, B.; Richir, M.C.; Van Agtmael, M.A. Urgent need to modernize pharmacovigilance education in healthcare curricula: Review of the literature. Eur. J. Clin. Pharmacol. 2018, 74, 1235-1248. [CrossRef] [PubMed]

52. Shchory, M.P.; Goldstein, L.H.; Arcavi, L.; Shihmanter, R.; Berkovitch, M.; Levy, A. The effect of an intervention program on the knowledge and attitudes among medical staff regarding adverse drug reaction reporting. Pharmacoepidemiol. Drug Saf. 2020, 29, 1246-1253. [CrossRef]

53. Griffith, R.; Griffiths, H.; Jordan, S. Administration of medicines part 1: The law and nursing. Nurs. Stand. 2003, 18, 47-53. [CrossRef]

54. The Nursing and Midwifery Council. Standards for Medicines Management. 2020. Available online: https://www.nmc.org.uk/ standards/standards-for-post-registration/standards-for-medicines-management/ (accessed on 9 June 2020).

55. Grissinger, M. The Five Rights: A Destination without a Map. Pharm. Ther. 2010, 35, 542.

56. Barnie, B.; Forson, P.K.; Opare-Addo, M.N.A.; Appiah-Poku, J.; Rhule, G.P.; Oduro, G.; Adu-Sarkodie, Y.; Donkor, P. Knowledge and Perceptions of Health Workers' Training on Ethics, Confidentiality and Medico-Legal Issues. J. Clin. Res. Bioeth. 2015, 6, 205. [CrossRef]

57. Institute for Healthcare Improvement. Improvement Stories: The Five Rights of Medication Administration. 2020. Available online: http:/ / www.ihi.org/resources/Pages/ImprovementStories/FiveRightsofMedicationAdministration.aspx (accessed on 9 June 2020).

58. Tanga, H.Y. Nurse Drug Diversion and Nursing Leader's Responsibilities. JONA's Healthc. Law Ethics Regul. 2011, 13, 13-16. [CrossRef]

59. O'Sullivan, D.; O’Mahony, D.; O’Connor, M.N.; Gallagher, P.; Cullinan, S.; O’Sullivan, R.; Gallagher, J.; Eustace, J.; Byrne, S. The Impact of a Structured Pharmacist Intervention on the Appropriateness of Prescribing in Older Hospitalized Patients. Drugs Aging 2014, 31, 471-481. [CrossRef] [PubMed]

60. Pearce, R.; Whyte, I. Editorial: Electronic medication management: Is it a silver bullet? Aust. Prescr. 2018, 41, 32-33. [CrossRef] [PubMed]

61. Lee, L.M. Ethics and subsequent use of electronic health record data. J. Biomed. Inform. 2017, 71, 143-146. [CrossRef] [PubMed]

62. Van Biesen, W.; Decruyenaere, J.; Sideri, K.; Cockbain, J.; Sterckx, S. Remote digital monitoring of medication intake: Methodological, medical, ethical and legal reflections. Acta Clin. Belg. 2019, 10, 1-8. [CrossRef] [PubMed]

63. Al Shemeili, S.; Klein, S.; Strath, A.; Fares, S.; Stewart, D. A modified Delphi study of structures and processes related to medicines management for elderly hospitalised patients in the United Arab Emirates. J. Eval. Clin. Pract. 2016, 22, 781-791. [CrossRef] [PubMed]

64. Mitty, E.; Resnick, B.; Allen, J.; Bakerjian, D.; Hertz, J.; Gardner, W.; Rapp, M.P.; Reinhard, S.; Young, H.; Mezey, M. Nursing Delegation and Medication Administration in Assisted Living. Nurs. Adm. Q. 2010, 34, 162-171. [CrossRef]

65. O'Sullivan, M.-J.; Rae, S. Shared decision-making in psychiatric medicines management. Ment. Health Pract. 2014, 17, 16-22. [CrossRef]

66. Kavanagh, C. Medication governance: Preventing errors and promoting patient safety. Br. J. Nurs. 2017, 26, 159-165. [CrossRef]

67. Vaismoradi, M.; Vizcaya-Moreno, F.; Jordan, S.; Kymre, I.G.; Kangasniemi, M. Disclosing and Reporting Practice Errors by Nurses in Residential Long-Term Care Settings: A Systematic Review. Sustainability 2020, 12, 2630. [CrossRef]

68. Aag, T.; Garcia, B.H.; Viktil, K.K. Should nurses or clinical pharmacists perform medication reconciliation? A randomized controlled trial. Eur. J. Clin. Pharmacol. 2014, 70, 1325-1332. [CrossRef]

69. Mardani, A.; Griffiths, P.; Vaismoradi, M. The Role of the Nurse in the Management of Medicines during Transitional Care: A Systematic Review. J. Multidiscip. Healthc. 2020, 13, 1347-1361. [CrossRef] [PubMed]

70. Afolalu, O.O.; Jordan, S.; Kyriacos, U. Medical error reporting among doctors and nurses in a Nigerian hospital: A cross sectional survey. J. Nurs. Manag. 2020. [CrossRef] [PubMed] 
71. Ferrah, N.; Lovell, J.J.; Ibrahim, J.E. Systematic Review of the Prevalence of Medication Errors Resulting in Hospitalization and Death of Nursing Home Residents. J. Am. Geriatr. Soc. 2017, 65, 433-442. [CrossRef] [PubMed]

72. Montesi, G.; Lechi, A. Prevention of medication errors: Detection and audit. Br. J. Clin. Pharmacol. 2009, 67, 651-655. [CrossRef]

73. Lawton, R.; Carruthers, S.; Gardner, P.; Wright, J.; McEachan, R. Identifying the Latent Failures Underpinning Medication Administration Errors: An Exploratory Study. Health Serv. Res. 2012, 47, 1437-1459. [CrossRef]

74. American Medical Association. Patient Rights: Code of Medical Ethics Opinion 1.1.3. 2020. Available online: https://www.amaassn.org/delivering-care/ethics / patient-rights (accessed on 9 June 2020).

75. Haw, C.M.; Stubbs, J. Covert administration of medication to older adults: A review of the literature and published studies. J. Psychiatr. Ment. Health Nurs. 2010, 17, 761-768. [CrossRef] [PubMed]

76. Munden, L.M. The Covert Administration of Medications: Legal and Ethical Complexities for Health Care Professionals. J. Law Med. Ethics 2017, 45, 182-192. [CrossRef]

77. Blignaut, A.J.; Coetzee, S.K.; Klopper, H.C.; Ellis, S.M. Medication administration errors and related deviations from safe practice: An observational study. J. Clin. Nurs. 2017, 26, 3610-3623. [CrossRef]

78. Martyn, J.-A.; Paliadelis, P.S.; Perry, C. The safe administration of medication: Nursing behaviours beyond the five-rights. Nurse Educ. Pract. 2019, 37, 109-114. [CrossRef]

79. Rose, R.V.; Kass, J.S. Prescribing Antipsychotic Medications to Patients with Dementia. Contin. Lifelong Learn. Neurol. 2019, 25, 254-259. [CrossRef] 